\title{
Caregiver attributes and socio-demographic determinants of caregiving burden in selected low-income communities in cape town, South Africa
}

\author{
Yakubu A. Yakubu* and De Wet Schutte
}

\begin{abstract}
Background: Informal caregivers play an important role in the well-being of dependent members in a household. Yet, literature on female caregiver burden in low-income and middle-income countries is scanty. This study examines the socio-demographic and socio-economic determinants of female caregiver burden in Cape Town, South Africa.

Methods: The cross-sectional study involved 100 black/African and 100 coloured female caregivers selected through a systematic random sampling procedure in two different cultural communities. The study instrument assessed caregiver burden with both objective and subjective measures through the use of a fully structured questionnaire. Chi-square tests and correlation analysis were used to examine the association between background characteristics and female caregiver burden.

Results: The results showed that a large proportion of caregivers (49.5\%) were in the age group of 50-59 years. The majority of the respondents were in care tasks as a full time job, providing more than $40 \mathrm{~h}$ of care per week. Statistical significant associations were found between the socio-demographic characteristics of female caregivers (such as age, education, population group and income status) and the physical health status of the care recipients. Further, physical health of care recipients and social grants showed strong, statistically significant positive correlations with caregiver burden.

Conclusions: The study recommends the government to recognise the importance of physical health of the care recipients and increase the amounts of social grants to the caregivers since this could improve the standard of living of both the care recipients and caregivers.
\end{abstract}

Keywords: Socio-demographic characteristics, Physical health, Caregiver burden, Low-income

\section{Background}

Informal caregivers are defined as people who provide unpaid care for the aged or for people needing physical, emotional, social and financial assistance with tasks in the home and spend much time and energy for long periods of time [1-3]. Research has shown that the majority of informal caregivers are women [2] and are primarily

\footnotetext{
* Correspondence: ysquare2001@gmail.com

Department of Environmental and Occupational Studies, Cape Peninsula University of Technology - CPUT, Corner of Keizersgracht and Tennant Street Zonnebloem, Contact Cape Town Campus, PO Box 652, Cape Town 8000, South Africa
}

members of the same family to whom care is given $[4,5]$. However, literature suggests that the caregiver may not be living with the care recipient (CR) [6]. This study focused on informal caregivers or family caregivers. The demographic and psychosocial characteristics associated with caregiver distress (e.g. depression, general psychological distress and physical strain) include being a woman, being younger in age, being the patient's spouse, having a lower socio-economic status, being employed and lacking personal and/or social support [7, 8]. As such, the burdens that caregiving present are multiple and pervasive and often contribute to guilt feelings, worry and grief $[9,10]$. 
In the role, caregiver burden occurs when caregivers perceive difficulty in performing their tasks, or feel overwhelmed by their tasks [11].

The chronic and demanding nature of family caregiving, especially in poverty-stricken households, can lead to a high degree of stress or caregiver burden and pressure on household and environmental health resources [12]. For example, the majority of the elderly in Lebanon live with their families who provide help when they are impaired, often with little formal resources for support [13]. The problem is compounded with advanced age that comes with associated health concerns or functioning problems and needs for activities of daily living (ADLs) [2]. In the search for answers to issues relating to caregiving dynamics, it has long been established that many of the frail, elderly persons living in the community rely on support from family and friends, which is usually provided informally by a non-family member, or a family female caregiver [10]. Most research on family care had reported that the caregivers bear the greater burden [14, 15]. Many of these researches on caregiver burden were concentrated on caregivers of chronically ill patients such as those with dementia, Alzheimer's disease and heart disease [9, 16-19]. There seems to be less focus on the wider caregiver roles, especially regarding caregivers of recipients who are not necessarily physically or mentally ill. Also, there is a paucity of research exploring the reactions to care for the elderly person, especially regarding the frail, older members in the household. However, caregivers' attributes/backgrounds, such as age, education and socio-economic status (SES) as well as environmental health may all play an important role in the well-being of the family. For these reasons, this study seeks to examine the socio-demographic and socio-economic determinants of female caregiver burden in two selected low-income communities (these are New Rest and New Woodlands) in Cape Town, South Africa. The study: (1) will explore the association between socio-demographic variables and the physical health of care recipients; (2) evaluate caregiving burden among the caregivers using a group of burden inventory variables; and, (3) determine the correlates of caregiving burden using correlation analysis; in the study sites. This will lead to these questions:

a) Is there a significant relationship between the attributes of the female caregivers and the physical health status of the care recipients under their care?

b) What are the correlates of caregiver burden among the female caregivers in the low-income areas?

In answering these questions, the following hypotheses were developed; a) Female caregiver socio-demographic attributes are significantly associated with perceived physical health.

b) The social grant provided by the government makes a significant difference in caregiver burden.

\section{Stress process Modelling}

The Pearlin model [20] views caregiver burden as a dynamic concept and many of the existing stress and coping models in the caregiving research tend to comprise of six core categories of variables: (1) context/demographic variables (e.g. gender, race, age, and relationship to recipient), (2) demands on caregiver (e.g. recipient's functional abilities and time spent caring), (3) appraised stressors associated with the caregiving situation (e.g. financial strain), (4) Personal demands (e.g. work status, family conflict, privacy), (5) Caregiver appraised buffers (e.g. active coping, social support), and (6) long-term consequences (e.g. emotional distress). However, the majority of the literature focuses only on a subset of these categories of constructs, and the measurement of these constructs is often limited to only a few of these variables.

It has been proven that combining the SPM with other provides a conceptual clarity [21] for modelling caregiving burden. In this study the combination of SPM and TMSC was ustilised to enable intuitive understanding of the stress process. The SPM [20] is largely consistent with the Lazarus and Folkman's [22] TMSC. Lazarus and Folkman's model provides a framework for explaining the processes involved when a person attempts to cope with stressful events. These models postulate that when individuals are confronted with a stressor, they evaluate the potential threats by making a primary appraisal that then integrates their judgement regarding the significance of the event (e.g. stressful or not stressful, negative or positive, controllable or uncontrollable). Thereafter, individuals make a secondary appraisal. Here, they assess their coping resources and the options at their disposal to help cope with the stressor. Therefore, the secondary appraisals help to address their actions to cope with the stressor. The SPM posits that positive outcomes such as psychological and physical well-being occur when adequate coping resources are available to deal effectively with the stressors, whereas negative outcomes such as mental health problems and illness result when stressors outweigh adequate coping resources [22]. For improved prediction possibility, two additional constructs based anecdotal evidence were integrated to assess caregiver burden among the study participants. These constructs were (i) environmental health factors and (ii) physical health of care recipients.

\section{Methods}

\section{Study design and setting}

This study was designed to collect data in accordance with SPM by Pearlin [20] through structure interviews with the 
focus on caregiver burden. The South Africa's apartheid past left a strong and obstinate racial character visibly evidenced in the country's poverty level and distributions of income and wealth. After decades of democratization in the country, the incidence of poverty among Black and Coloured individuals remained significantly higher than that among whites. The population distributions of the country are $80.1 \%$ Black, $8.7 \%$ Coloured, $2.5 \%$ Indians and $8.6 \%$ Whites. The poverty incidence among population groups (race) being 54.8\% Blacks, 34.2\% Coloured, 7.1\% Indians and $0.4 \%$ Whites. Some groups such as blacks, female-headed households, the aged, less educated individuals, the unemployed South Africans experience poverty more intensely [23]. Owing to its constitutional commitment the Government of South Africa came up with policy initiatives to ensure income security. As part of these policies, the Child Support Grant which is means-tested was initiated in 1998 and available to the primary caregiver of eligible children under the age of 15 years. Two geographical areas with low-income, predominantly black and coloured communities that consist of mainly government subsidised housing (formal settlement) in Cape Town, were selected for the study. A pilot survey preceded the main study as a feasibility study to test the study instrument for reliability and consistency in the questions. The two communities randomly selected in the identified areas, were New Rest in Gugulethu and New Woodlands in Mitchells Plain. Caregivers' characteristics and background variables such as socio-economic status and socio-demographics status information were gathered. The Stress Process Model was used to identify the main types of social support which included: (i) Instrumental (e.g. whether someone is there to assist the caregiver); and (ii) Expressive support (e.g. whether there is a trustworthy person in whom the caregiver can confide). Prior to the main study, a pilot study was conducted on 60 participants who were randomly recruited. The pilot study was used to gauge the respondents' understanding of the questionnaire and to test the face validity and internal reliability of the structured questionnaire. From the results of the pre-test, the study instrument was refined and certain questions were rephrased to allow for a more feasible capturing of data from the returned questionnaires.

\section{Data source}

Data were collected from two different low-income cultural communities (i.e. black/African dominant and Coloured dominant settlements) settings in Cape Town, South Africa. The data were made up of 100 female caregivers selected from each setting using a systematic random sampling (SRS) procedure. A total sample size of 200 female caregivers was selected. The Statistics South Africa Quarterly Labour Force Survey database for the study sites was used for sampling. The primary sampling unit (PSU) was the dwelling unit (DU) or housing unit (in which the respondents live), for this study (in which both the caregiver and the care recipient lived). With a random start, DUs were systematically selected at random from the total number of the sample units in included in the study site. DUs without the criteria for inclusion were excluded.

Inclusion criteria for the respondents were the main/primary female caregivers who were present, willing and able to give informed consent. A caregiver was defined as having an elderly person and/or a non-biological childcare recipient/s under her care and living in a formal settlement (areas demarcated and developed by state or developers). In this study caregivers for both elderly person and child were combined. This is because many caregivers have both elderly person and child and was difficulty to group them separately for analysis due. Any sampled dwelling units that blend into shanty or shack areas were excluded. Also, all such dwelling units that formed part of the pilot study were excluded in the main study.

\section{Outcome variable}

The main outcome (measure) of this study is the caregiving mental health or emotional feeling (caregiving burden). This is consistent with the effects of interest in the social research; (i) female caregivers' well-being, and (ii) their physical and mental health.

\section{Data analysis}

Female caregiver burden was computed using eight items/ variables which focused on financial burden, lack of privacy, sleep disturbance, physical burden, change in lifestyle, insufficient level of funds, suffered social life and no control over one's life.

Functional status of the care recipient (CR) was assessed by using the activities of daily living and instrumental activities of daily living. The activities of daily living included difficulties caregivers experienced with feeding, cooking, dressing, bathing and washing the clothes of CR. The instrumental activities of daily living included $\mathrm{CR}$ user needs (i.e. wheel chair, spectacles, walking stick and transport). The instrumental activities of daily living scores were created by adding the items in each of the functional status assessments. A higher score indicated a more dependent functional status. Further, a principal component factor analysis was performed, and showed that each of the items for activities of daily living and instrumental activities of daily living measured one latent variable. The reliability test showed that the Cronbach's alpha for items of activities of daily living was 0.909 and that of instrumental activities of daily living was 0.836 .

Descriptive statistics were used to show background characteristics and the socio-demographic characteristics of caregivers. Chi-square tests were used to show the association between socio-demographic / background 
variables and the physical health of care recipients. Correlation was used to examine the correlates of caregiving burden. Female caregiver was measured with each item/ variable rated on a two-point scale [(yes $=1),(\mathrm{No}=0)]$, with higher scores indicating higher caregiver burden. The mean score in each item was determined at a 95\% confidence interval (CI). Also, Pearson correlation analyses were used to examine correlation between each variable and caregiver burden at 95\% CI. The data were analysed using SPSS version 22. The following sections present the results found in this study.

\section{Results}

\section{Socio-demographic characteristics of caregivers Description statistics}

The average age of female caregivers was 47.9 years (standard deviation $(\mathrm{SD})=11.7$ years). A greater proportion of the respondents (caregivers) were older. All caregivers had at least Grade 1 education with the majority having completed some secondary education (Grade 811). Many of them were never married, and about one in three caregivers were currently married and a small proportion was cohabiting. It was deduced that majority of the caregivers earned less than R1001 (Table 1).

The caregiving role was a full time task as a large proportion provided care for more than $40 \mathrm{~h}$ per week, without supportive caregiving programmes. There was no spousal caregiving relationship in the sample. It is also deduced that more than $40 \%$ were in the caregiving role for more than 3 years. The average number of activities of daily living in which care recipients needed assistance was $3.5(\mathrm{SD}=1.94)$, and the average number of needs for instrumental activities of daily living was $1.62(\mathrm{SD}=1.60)$ (Table 2).

\section{Care demands and physical health of care recipients}

The age, population group, level of education, income, employment status, duration of caregiving and care hours per week were significantly associated with the physical health of the caregivers (Table 3). However, marital status was not significantly associated with caregivers' physical health.

\section{Prevalence of caregiving burden}

There is a moderate-higher burden due to caregiving. The highest reported burden was lack of privacy in caregiving tasks. Physical and Finance burden on the caregiver was reported the least burden in the caregiving responsibility (Table 4).

\section{Correlation predictors of caregiver burden}

Table 5 shows the Pearson correlation analyses for the determinants of caregiver burden. The results suggest that there were significant positive relationships between female caregiver burden and age, income status,
Table 1 Descriptive analysis of socio-demographic characteristics of caregivers

\begin{tabular}{|c|c|c|}
\hline Characteristics and profile & & \\
\hline Mean age in years(SD) & $47.89(11.7)$ & \\
\hline Characteristics & $\%$ & $n$ \\
\hline \multicolumn{3}{|l|}{ Population Group } \\
\hline Black & 50.0 & 100 \\
\hline Coloured & 50.0 & 100 \\
\hline Total & 100.0 & 200 \\
\hline \multicolumn{3}{|l|}{ Education } \\
\hline$<$ Grade 7 & 1.5 & 3 \\
\hline Grade 7/Standard 5 & 9.0 & 18 \\
\hline Grade 8-11 & 54.0 & 108 \\
\hline Standard 10/(Grade 12) & 31.0 & 62 \\
\hline Higher & 4.5 & 9 \\
\hline Total & 100.0 & 200 \\
\hline \multicolumn{3}{|l|}{ Age Group (years) } \\
\hline$<30$ & 11.5 & 23 \\
\hline $30-39$ & 11.5 & 23 \\
\hline $40-49$ & 21.5 & 43 \\
\hline $50-59$ & 49.5 & 99 \\
\hline 60 and above & 6.0 & 12 \\
\hline Total & 100.0 & 200 \\
\hline \multicolumn{3}{|l|}{ Income } \\
\hline $\mathrm{RO}-\mathrm{R} 500$ & 39.8 & 80 \\
\hline R501 - R1000 & 18.3 & 36 \\
\hline R1001 - R2000 & 39.3 & 79 \\
\hline R2001 and above & 2.6 & 5 \\
\hline Total & 100.0 & 200 \\
\hline \multicolumn{3}{|l|}{ Marital status } \\
\hline Never married & 28.1 & 56 \\
\hline Formerly married & 33.7 & 68 \\
\hline Cohabitation & 6.0 & 12 \\
\hline Currently married & 32.2 & 64 \\
\hline Total & 100.0 & 200 \\
\hline
\end{tabular}

activities of daily living (ADL), chronic diseases, social grants, kitchen hygiene and the physical health of care recipients in the various constructs $(p<0.05$; Table 5$)$. Similarly, there were significant moderately negative relationships between caregiver burden and population group, employment status and number of hours they spent in care per week $(p<0.05$; Table 5$)$.

Older female caregivers with a lower income will experienced significantly higher burden than those who are older with higher income bracket $(r=0.314$, $\mathrm{p}<0.05$; Table 5). Lesser burden is associated with caregivers who have formal education, work more 
Table 2 Descriptive analysis of female caregiving demands

\begin{tabular}{|c|c|c|}
\hline Characteristics & Percent & Number \\
\hline \multicolumn{3}{|c|}{ Care Hours per week } \\
\hline$<10$ & 23.2 & 47 \\
\hline $10-19$ & 20.7 & 41 \\
\hline $20-29$ & 6.6 & 13 \\
\hline $30-39$ & 8.6 & 17 \\
\hline 40 and above & 40.9 & 82 \\
\hline Total & 100.0 & 200 \\
\hline \multicolumn{3}{|c|}{ Duration of caregiving } \\
\hline$<1$ year & 24.0 & 48 \\
\hline $1-2$ years & 35.5 & 71 \\
\hline $3-5$ years & 23.5 & 47 \\
\hline 6 and above & 17.0 & 34 \\
\hline Total & 100.0 & 200 \\
\hline \multicolumn{3}{|c|}{ CR Relationship to caregiver } \\
\hline Niece & 2.5 & 5 \\
\hline Cousin & 64.0 & 128 \\
\hline Brother & 1.0 & 2 \\
\hline Sister & 15.0 & 30 \\
\hline Grandson & 17.0 & 34 \\
\hline Granddaughter & 0.5 & 1 \\
\hline Total & 100.0 & 200 \\
\hline \multicolumn{3}{|l|}{ Programme Use } \\
\hline Yes & 1.6 & 3 \\
\hline No & 98.4 & 197 \\
\hline Total & 100.0 & 200 \\
\hline \multicolumn{3}{|c|}{ Functional dependence } \\
\hline$A D L s^{a}$ & $3.51(1.94)$ & \\
\hline IADLs $s^{\mathrm{b}}$ & $1.62(1.60)$ & \\
\hline
\end{tabular}

${ }^{\mathrm{a}} A D L s$ Activities of daily living ${ }^{\mathrm{b}}$ IADLs Instrumental activities of daily living

hours and received family support (Table 5). Age interacts with education level, population group, number of hours in care, family support receive to lessen the caregiver burden. In contrast, age interacts with income status, marital status, chronic diseases, social agent, kitchen hygiene, and care recipient physical health to worsen the caregiver burden (Table 5). With the exception of educational level which interacts with chronic diseases to reduce caregivers burden, most determinants interact with chronic diseases to increase caregiver burden $(p<0.05$; Table 5$)$.

\section{Discussions}

Stress Process Model (SPM) was used to examine the socio-demographic and socio-economic determinants of female caregiver burden in Cape Town, South Africa.
We examined caregiving burden among the caregivers; and the correlates of caregiving burden among the study participants. The finding of the present study indicates that many socio-economic and demographic determinants interact to increase the caregiver burden in-low income settings in Cape Town, South Africa. Many factors contributing to caregivers' burden include lack of privacy, sleep disturbance and social life status. On the other hand, physical and finance burden on the caregiver was reported to be least contributor of caregiver burden. A greater proportion of the caregivers were older which was a significant determinant of caregiver burden. Our study shows a significant increase in caregiver burden with age, income level, ADL, chronic diseases, kitchen hygiene and recipient physical health status.

Our finding that low-income caregivers experience more burden than caregivers with higher income is consistent with previous research findings $[24,25]$. Moreover, other studies posit in a study of children with serious emotional disturbance, socio-economic status proved to be an important predictor of caregiver stress [26] which is in line with our funding that care recipient with physical health needs worsen caregiver burden. The case of higher income could be due to the primary caregiver having a paid job outside or doing part time job and not always present to give fulltime primary care. Our finding that physical burden is the least reported burden is consistent with recent reports (see [2]). Kim et al. [27] also found small to moderate positive relationships between caregiving-related factors and caregiver burden which collaborated our findings. Though, greater proportion of the caregivers had some form of secondary education, they have higher burden with increasing age which is in contrast with the finding of, Umaru et al. [2] that caregivers education and training is an important factor in order to enhance caregivers' ability to cope effectively with the brunt of burden of providing care to care recipients who have impairment of physical function. A large proportion of caregivers were single and about one in three caregivers were currently married. This study found that majority of the caregivers earned low-income (i.e. less than R1001 pm). This could be explained by the type of residential area (government subsidized housing settlements for low-income areas earners). Further, this could be the reason for the significant burden experienced by the caregivers in this study, and supported by work of Williams et al. [25] that there is positive relation between income and burden. Empirical evidence in Ghana also showed this relationship (see [8]).

From Pearlin [20] caregiving and its consequences are greatly influenced by the caregiver background characteristics. Analysis herein points to weaker background attributes. This has a negative effect on their ability to evaluate 
Table 3 Socio-demographic characteristics, demands and physical health of care recipients

\begin{tabular}{|c|c|c|c|c|c|c|}
\hline \multirow[t]{2}{*}{ Background Characteristics } & \multirow{2}{*}{$\begin{array}{l}\text { Very Good } \\
n=64\end{array}$} & \multirow{2}{*}{$\begin{array}{l}\text { Good } \\
n=104\end{array}$} & \multirow{2}{*}{$\begin{array}{l}\text { Bad } \\
n=32\end{array}$} & \multirow[t]{2}{*}{ Total } & \multirow[t]{2}{*}{$x^{2}$} & \multirow[t]{2}{*}{$P$-Values } \\
\hline & & & & & & \\
\hline \multicolumn{7}{|l|}{ Age Group } \\
\hline Less than 30 & 9.5 & 0.5 & 1.5 & 11.5 & \multirow[t]{4}{*}{58.668} & \multirow[t]{4}{*}{$0.000^{*}$} \\
\hline $30-39$ & 5.5 & 2.5 & 3.5 & 11.5 & & \\
\hline $40-49$ & 4.0 & 13.0 & 4.5 & 21.5 & & \\
\hline 50 and above & 13.0 & 36.0 & 6.5 & 55.5 & & \\
\hline \multicolumn{7}{|l|}{ Population Group } \\
\hline Black/African & 2.5 & 44.0 & 3.5 & 50.0 & \multirow[t]{2}{*}{105.534} & \multirow[t]{2}{*}{$0.000^{*}$} \\
\hline Coloured & 29.5 & 8.0 & 12.5 & 50.0 & & \\
\hline \multicolumn{7}{|l|}{ Education Level } \\
\hline$<$ Grade 7 & 0.5 & 1.0 & 0.0 & 1.5 & \multirow[t]{4}{*}{16.535} & \multirow[t]{4}{*}{$0.035^{*}$} \\
\hline Grade $7 /$ Standard 5 & 3.0 & 3.0 & 3.0 & 9.0 & & \\
\hline Grade 8-11 & 15.6 & 32.2 & 6.0 & 53.8 & & \\
\hline Grade 12 and higher & 13.1 & 15.6 & 7.0 & 35.7 & & \\
\hline \multicolumn{7}{|l|}{ Income } \\
\hline R0 - R500 & 23.6 & 6.8 & 9.4 & 39.8 & \multirow[t]{3}{*}{78.325} & \multirow[t]{3}{*}{$0.000^{*}$} \\
\hline R501 - R1000 & 2.1 & 14.7 & 1.7 & 18.5 & & \\
\hline R1001 and above & 5.2 & 32.4 & 4.1 & 41.9 & & \\
\hline \multicolumn{7}{|l|}{ Marital status } \\
\hline Never married & 9.5 & 16.1 & 2.5 & 28.1 & \multirow[t]{3}{*}{10.756} & \multirow[t]{3}{*}{0.096} \\
\hline Formerly married & 10.6 & 18.6 & 4.5 & 33.7 & & \\
\hline Currently married & 12.0 & 17.1 & 9.0 & 38.2 & & \\
\hline \multicolumn{7}{|l|}{ Employment status } \\
\hline Employed & 3.5 & 23.6 & 3.5 & 30.6 & \multirow[t]{4}{*}{45.817} & \multirow[t]{4}{*}{$0.000^{*}$} \\
\hline Unemployed & 7.5 & 16.1 & 1.5 & 25.1 & & \\
\hline Not economically active & 13.1 & 9.5 & 6.0 & 28.6 & & \\
\hline Housewife & 8.0 & 2.5 & 5.0 & 15.6 & & \\
\hline \multicolumn{7}{|l|}{ Duration of caregiving (years) } \\
\hline$<1$ year & 2.5 & 19.0 & 2.5 & 24.0 & 34.597 & $0.000^{*}$ \\
\hline $1-2$ years & 12.5 & 20.0 & 3.0 & 35.5 & & \\
\hline $3-5$ years & 9.0 & 8.0 & 6.5 & 23.5 & & \\
\hline $6-10$ years & 5.0 & 3.5 & 3.5 & 12.0 & & \\
\hline$>10$ years & 3.0 & 1.5 & 0.5 & 5.0 & & \\
\hline Care hours per week & & & & & & \\
\hline$<10 \mathrm{~h}$ & 1.5 & 19.7 & 2.0 & 23.2 & 105.1 & $0.000^{*}$ \\
\hline $10-19$ & 1.0 & 18.2 & 1.5 & 20.7 & & \\
\hline $20-29$ & 0.5 & 6.1 & 0.0 & 6.6 & & \\
\hline $30-39$ & 6.6 & 1.5 & 0.5 & 8.6 & & \\
\hline 40 and above & 22.2 & 7.1 & 11.6 & 40.9 & & \\
\hline
\end{tabular}

${ }^{*} P<0.05$

the potential threats by making a primary appraisal that then integrates their judgement regarding the significance of the event. This is consistent with finding that more than half of the caregivers were burdened.
In terms of the caregiving contexts and demands, the findings from this study show that the care recipients needed more assistance in activities of daily living than in instrumental activities of daily living. For number of 
Table 4 Prevalence of caregiving burden

\begin{tabular}{lll}
\hline Burden of caregiving & Mean & $95 \% \mathrm{Cl}$ \\
\hline Lack of privacy & 2.88 & $2.79-2.97$ \\
Sleep disturbance & 2.65 & $2.57-2.73$ \\
Physical burden & 2.13 & $2.07-2.19$ \\
Change in life due to caregiving & 2.57 & $2.50-2.64$ \\
Finance burden experience & 2.09 & $2.03-2.15$ \\
Inadequate finance in caregiving & 2.25 & $2.18-2.32$ \\
Social life status & 2.62 & $2.54-2.70$ \\
Life control of CR & 2.25 & $2.19-2.31$ \\
\hline$C l$ Confidence interval & & \\
${ }^{*} P<0.05$ & &
\end{tabular}

hours in care provision, about half of the caregivers provided for long hours per week, with half of them in care provision like fulltime job (i.e. providing care for more than $40 \mathrm{~h}$ per week). A large proportion was in the role for many years. Only about a quarter of the caregivers were in care for less than a year and almost half of them were in it for more than 3 years. Almost all the caregivers took care of their sisters, grandsons and cousins. About 6 in 10 of the caregivers took care of their cousins. Almost all the caregivers had no access to any form of caregiving supportive programme to help cope with the brunt of caregiving. Receiving support could increase the resources for care provision by the caregiver in the role that could reduce the burden that could have emanated from inadequate resources [8]. The SPM posits that positive outcomes such as psychological and physical well-being occur when adequate coping resources are available to deal effectively with the stressors, whereas negative outcomes such as mental health problems and illness result when stressors outweigh adequate coping resources. From the foregoing analysis, the caregivers were exposed to the stressors without adequate resources to help cope with the brunt of caregiving, hence the negative appraisal of caregiving.

Our study results are consistent with previous work that reported that for perceived physical health, there were ethnic differences for the effect of income, gender, and type of caregiver relationships [28]. The caregivers in higher income bracket were perceived to be physically healthier than those in the lower income bracket. This finding is not surprising that employment status was positively to better caregiver physical health because it collaborates the finding that those caregivers with higher income were more resourced (see [8], for the effect of resources).

With respect to care demands or tasks, the study found that caregivers who were in the provision for fewer years at the time of the interview reportedly had better perceived physical health when compared with the caregivers who were in it for many years. It was however, found that being in the caregiver role providing care for longer hours per week like fulltime job ( $40 \mathrm{~h}$ or more per week) found the care provision as more rewarding in terms of their perceived physical health.

This study found that the female caregivers in the study areas were burdened. They were small to moderate positive relationships between female caregiver burden and the group of burden predictors (age, education level, income status, activities of daily living, chronic diseases, social grants, kitchen hygiene and the physical health of care recipients). These findings are consistent with the work of Kim et al. [27] regarding predictors of caregiver burden in caregivers of individuals with dementia, that reported activities of daily living and/or instrumental activities of daily living, number of hours spent in caregiving per week, use of coping strategies, co-residence, spousal status and caregiver gender as significant $(P<0.05)$ factors of caregiver burden. Also, Iwata and Horiguchi [29] reported consistent findings.

It has been reported that as the caregiver engages in instrumental activities in an effort to provide care to the care recipient, such activities can interfere with other aspects of his or her life, including relationships with other family members, personal privacy or work-related aspects, which could potentially result in stress burden [24, 29, 30]. A positive relationship between time in assisting with activities of daily living and objective burden has also been posited [30]. However, the results established statistically significant correlations between caregiver burden and population group, employment status and number of hours they spent in care per week. The literature suggests that caregiving duties affect the level of income resulting from reduced hours of work or stopping work completely [31]. For activities of daily living, other studies show that greater impairment of care recipients is associated with a higher burden of caregiving [27, 32].

Findings from the current study offer important contributions to the realm of caregiving research. In contrast to previous studies, this research showed that a combination of the Stress Process Model and TMSC and inclusion of environmental hygiene factors could offer a more indepth perspective to informal caregivers' burden. To our knowledge, this is the first paper in the caregiving burden literature to combine variables from these two models and environmental hygiene factors in order to investigate informal caregivers' burden. The findings confirm the stress process model that emphasizes the multidimensional nature of the correlates of caregiver burden. The study has shown a general pattern of moderate-higher burden resulting from caregiving. Among the burden inventory items, the highest reported burden was lack of privacy due to caregiving tasks. Overall, physical health of care recipients and social grants showed strong, statistically significant positive correlations with caregiver burden. 


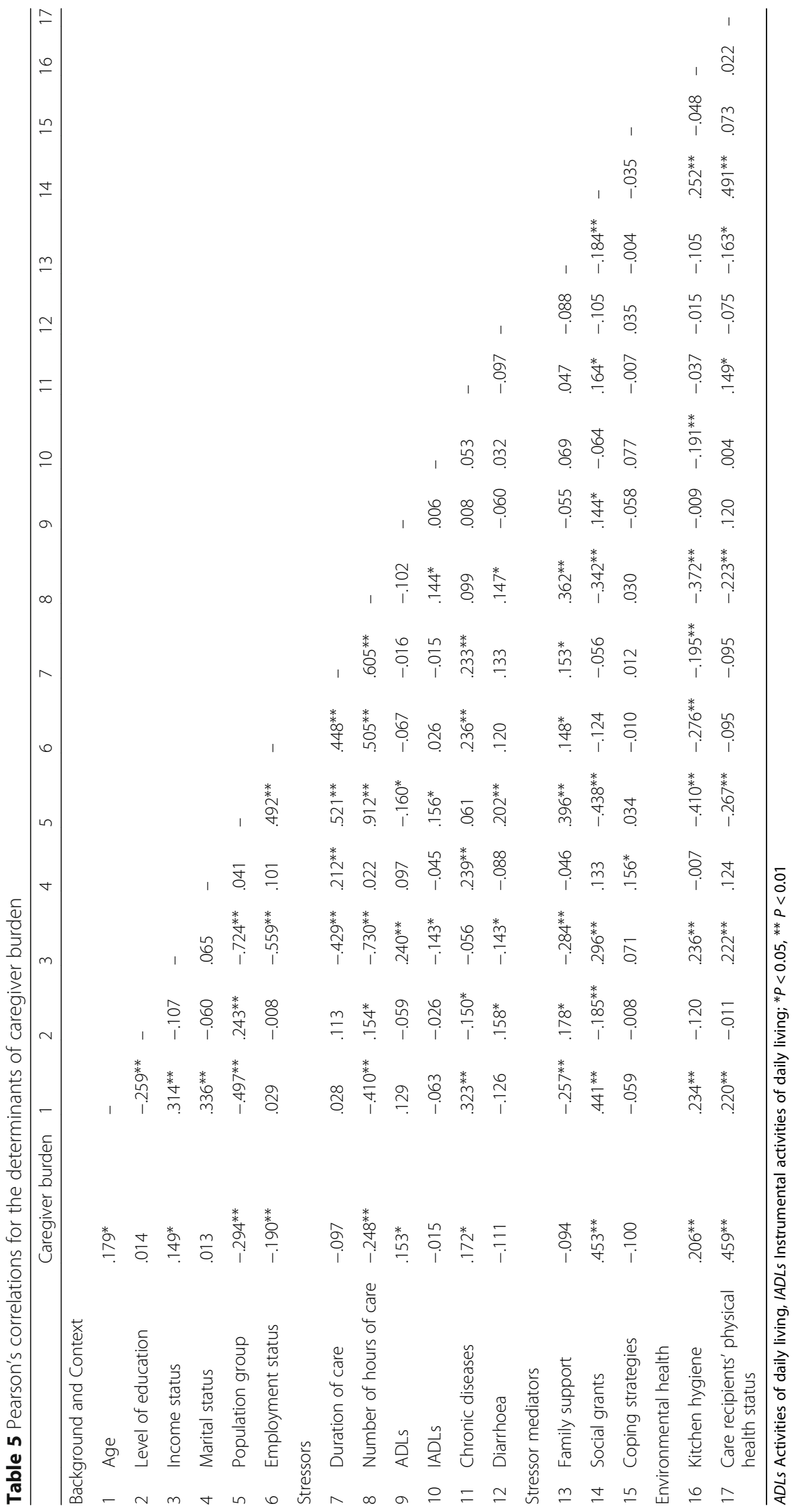




\section{Limitations}

A major limitation was that the study captured data that was provided at a specific point in time as the caregiver's current experience and thus cannot be used to generalise findings across time, (i.e. past and future) with confidence. Another limitation was that the interview focused on the primary caregiver, including caregivers providing care for only a few hours, for example less than $10 \mathrm{~h}$ per week. Due to the complexity of the caregiving situations noted during feedback from the interviewers, further probing questions ought to have been done on the caregiving situation, to know who else was present to provide care in the absence of the main caregiver. The import of this is that the services of a second major caregiver could help ameliorate the negative effect of caregiving on the main caregiver. In addition, the study could not identify and separate caregivers for the elderly persons and children for analysis.

\section{Conclusions}

This study has shown that the majority of the caregivers were aged, and most of the caregivers had no primary education and earned income less than R1001. The care recipients needed more assistance in activities of daily living than in instrumental activities of daily living.

Also, for physical health of the care recipients, the caregivers' attributes that are significant in determining caregiver burden, are age, population group, income and employment status. These findings buttress the important relationship between the socio-demographic variables (attributes) of female caregivers and the health of care recipients. Further, physical health of care recipients and social grants showed strong, statistically significant positive correlations with caregiver burden.

\section{Recommendations}

In a country where community caregivers play a significant role in supplementing and redressing the historical effects of racial segregation, as well as supporting the reform of the post-Apartheid health system, the plight of the caregivers must take centre stage in national health and development policies.

The government should recognise the increasing importance of the physical health of care recipients and increase the amount of the social grants to the caregivers, since this could improve the circumstances of both the caregiver and the care recipients. This kind of intervention will also help in reducing the burden on the government to provide more formal care institutions for care recipients. It could aid in improving the standard of living of caregivers in these households which will in turn also improve care received by the care recipients.

\section{Abbreviations}

ADLs: Activities of daily living; CG: Caregiver; CPUT: Cape Peninsula university of technology; CR: Care recipients; IADLs: Instrumental activities of daily living; SD: Standard deviation; SES: Socio-economic status; SPM: Stress process model; SPSS: Statistical package for social sciences;

TMSC: Transactional model of stress and coping

\section{Acknowledgements}

We acknowledge anyone who contributed towards the $\mathrm{PhD}$ research who does not meet the criteria for authorship in this article. We are grateful to Dr. O. Sanuade for the critigues of our statistical results, Ms. S.J. Mdlankomo and Ms. J.L. Abrahams for the data collection.

\section{Funding}

Cape Peninsula University of Technology Research Fund (URF).

\section{Availability of data and materials}

Please contact author for data requests.

\section{Declarations}

Ethics clearance (Ref 07/2013) was approved by the Ethics Committee of Cape Peninsula University of Technology.

\section{Authors' contributions}

YY led the conception and design, collection and analysis of data, interpretation of results and manuscript write up. DW made substantial contributions to the conception and design of the study and provided guidance in manuscript write up. Both authors read and approved the final manuscript.

\section{Ethics approval and consent to participate}

The ethics committee of the Faculty of Applied Sciences of CPUT provided the ethical clearance for this study. Furthermore, each individual female caregiver in the study completed a consent form.

\section{Consent for publication}

Consent to publish the findings of this research in a grouped data was given in the written informed consent.

\section{Competing interests}

The authors declare that they have no competing interests.

\section{Publisher's Note}

Springer Nature remains neutral with regard to jurisdictional claims in published maps and institutional affiliations.

Received: 10 October 2017 Accepted: 17 January 2018

Published online: 30 January 2018

References

1. Biegel DE, Sales E, Schulz R. Family caregiving in chronic illness: Alzheimer's disease, cancer, heart disease, mental illness, and stroke. Family caregiver applications series, Vol. 1. Thousand Oaks: Sage Publications, Inc; 1991.

2. Umaru MB, Omoyemi OO, Ade FA, Ekechukwu EN. Determinants of caregiving burden and qualityof life of informal caregivers of African stroke survivors: literature review. Int J Disabil Hum Dev. 2017;16(3):249-58.

3. van Pletzen $\mathrm{E}$, MacGregor $\mathrm{H}$. Multi country research on community caregivers: the backbone of accessible care and support - South Africa report. The Caregivers Action Network. 2013.

4. Chadiha LA, Adams P, Biegel DE, Auslander W, Gutierrez L. Empowering African American women informal caregivers: a literature synthesis and practice strategies. Soc Work. 2004;49(1):97-108.

5. Ogunmefun C, Gilbert L, Schatz E. Older female caregivers and HIV/AIDS-related secondary stigma in rural South Africa. J Cross Cult Gerontol. 2011;26:85-102

6. Hung J, Huang Y, Chen J, Liao L, Lin C, Chuo C, et al. Factors associated with strain in informal caregivers of stroke patients. Chang Gung Med J. 2012;35:392-401.

7. Kim Y, Given BA. Quality of life of family caregivers of cancer survivors. Cancer. 2008;112(S11):2556-68.

8. Sanuade OA, Boatemaa S. Caregiver profiles and determinants of caregiving burden in Ghana. Public Health. 2015;129(7):941-7. 
9. Biegel DE, Milligan SE, Putnam PL, Song LY. Predictors of burden among lower socioeconomic status caregivers of persons with chronic mental illness. Community Ment Health J. 1994;30(5):473-94.

10. Rose JH, Bowman KF, O'Toole EE, Abbott K, Love TE, Thomas C, Dawson NV. Caregiver objective burden and assessments of patient-centered, familyfocused care for frail elderly veterans. The Gerontologist. 2007:47(1):21-33.

11. Archbold PG, Stewart BJ, Greenlick MR. Mutuality and preparedness as predictors of caregiver role strain. Res Nurs Health. 1990;13(6):375-84.

12. Silver HJ, Wellman NS. Family caregiver training is needed to improve outcomes for older adults using home care technologies. J Am Diet Assoc. 2002:102(6):831-6.

13. Seoud J, Nehme C, Atallah R, Zablit C, Yeretzian J, Lévesque L, Giroux F, Ducharme $F$. The health of family caregivers of older impaired persons in Lebanon: an interview survey. Int J Nurs Stud. 2007;44(2):259-72.

14. Carretero S, Garcés J, Ródenas F, Sanjosé V. The informal caregiver's burden of dependent people: theory and empirical review. Arch Gerontol Geriatr. 2009:49(1):74-9.

15. Jorge G, Carretero S, Ródenas F, Carmen A. The care of the informal caregiver's burden by the Spanish public system of social welfare: A review. Archives of Gerontology and Geriatrics. 2010;50(3):250-53.

16. Adewuya AO, Owoeye OA, Erinfolami AR. Psychopathology and subjective burden amongst primary caregivers of people with mental illness in southwestern Nigeria. Soc Psychiatry Psychiatr Epidemiol. 2011;46(12):1251-6.

17. Demirtepe-Sayglı $D$, Bozo O. Predicting depressive symptoms among the mothers of children with leukaemia: a caregiver stress model perspective. Psychol Health. 2011;26(5):585-99.

18. Gbiri CA, Olawale OA, Isaac SO. Stroke management: informal caregivers; burdens and strians of caring for stroke survivors. Ann Phys Rehabil Med. 2015;58:98-103.

19. Matthews BA, Baker F, Spillers RL. Family caregivers and indicators of cancer-related distress. Psychol Health Med. 2003;8(1):46-56.

20. Pearlin LI, Mullan JT, Semple SJ, Skaff MM. Caregiving and the stress process: an overview of concepts and their measures. The Gerontologist. 1990;30(5):583-94.

21. Bastawrous M. Caregiver burden - a critical discussion. Int J Nurs Stud. 2013; 50(3):431-41.

22. Lazarus RS \& Folkman S. Stress, appraisal, and coping. Springer publishing company. 1984

23. Statistics South Africa. Income and expenditure survey 2005/06. Pretoria. 2008a.

24. Mello JA, Macq J, Van Durme T, Cès S, Spruytte N, Van Audenhove C and Declercq A. The Determinants of Informal Caregivers' Burden in the Care of Frail Older Persons: A Dynamic and Role-Related Perspective. Aging Ment Health. 2016:21 (8):838-43. https://doi.org/10.1080/13607863.2016.1168360.

25. Williams AM, Forbes DA, Mitchell J, Essar M, Corbett B. The influence of income on the experience of informal caregiving: policy implications. Health Care Women Int. 2003;24(4):280-91.

26. McDonald TP, Gregoire TK, Poertner J, Early TJ. Building a model of family caregiving for children with emotional disorders. J Emot Behav Disord. 1997;5(3):138-48.

27. Kim H, Chang M, Rose K, Kim S. Predictors of caregiver burden in caregivers of individuals with dementia. J Adv Nurs. 2012a;68(4):846-55.

28. Pinquart M, Sorensen S. Ethnic differences in stressors, resources, and psychological outcomes of family caregiving: a meta-analysis. The Gerontologist. 2005;45(1):90-106.

29. Iwata N, Horiguchi K. Differences in caregivers' psychological distress and associated factors by care recipients' gender and kinship. Aging Ment Health. 2015.

30. Savundranayagam MY, Montgomery RJ, Kosloski K. A dimensional analysis of caregiver burden among spouses and adult children. Gerontologist. 2011; 51(1):321-31.

31. Thrush A, Hyder A. The neglected burden of caregiving in low-and middleincome countries. Disabil Health J. 2014;7:262e72.

32. Conde-Sala JL, Garre-Olmo J, Turró-Garriga O, Vilalta-Franch J, López-Pousa S. Differential features of burden between spouse and adult-child caregivers of patients with Alzheimer's disease: an exploratory comparative design. Int J Nurs Stud. 2010;47(10):1262-73.

\section{Submit your next manuscript to BioMed Central and we will help you at every step:}

- We accept pre-submission inquiries

- Our selector tool helps you to find the most relevant journal

- We provide round the clock customer support

- Convenient online submission

- Thorough peer review

- Inclusion in PubMed and all major indexing services

- Maximum visibility for your research

Submit your manuscript at www.biomedcentral.com/submit

) Biomed Central 